natural rights, Nozik concentrates on only two of those rights; the right to life - that is, not to be unjustly killed - and the right to have possessions. Nozik argues that provided people acquire and transfer their "holdings" without violating others' rights no one is entitled to take them away. On that basis he argues that any taxation, beyond what is necessary to maintain the "minimal state" required to protect life and holdings, "is on a par with forced labour."

Nozik's arguments have provoked vigorous philosophical response. ${ }^{15}$ One of the criticisms is that if the whole spectrum of Lockean rights allegedly of concern to Nozik is to be protected his conclusions against taxation to benefit the poor and sick and otherwise disadvantaged are unsupported by his theory.

\section{Utilitarian theories}

Utilitarian theories emphasise that people deserve to have their welfare maximised. The danger of such theories is that in their simplistic versions they give too little weight to Lockean personal rights, which they are prepared to override whenever to do so is likely to maximise overall welfare. As I have indicated in my articles on utilitarianism and autonomy sophisticated utilitarian theories from Mill onwards have shown awareness of these dangers and have incorporated moral concern for personal liberty (in the sense of autonomy) as a required condition of maximisation of welfare. Professor R M Hare's form of utilitarianism sees the formal principle of justice as "nothing but a restatement of the requirement that moral principles be universalisable"-a principle that according to Hare is manifested in Bentham's principle that everybody counts for one and nobody for more than one. ${ }^{16}$

\section{Marxist theories}

Marxist theories of justice emphasise that people deserve to have their needs met; people's "deserts" are thus in direct proportion to their needs and Aristotle's formal principle of justice can be met by making needs the relevant inequality. Apart from conceptual problems-What are needs?-Marxist moral theory faces objections similar to those levelled at simplistic utilitarianism-notably, that other moral concerns, particularly respect for individual autonomy, may be overriden in order to satisfy human needs. The Marxist corollary of "to each according to his needs" is "from each according to his ability," and the operation of this rule, according to Lenin, results in "actual equality." ${ }^{\prime \prime}$ It is a rule that, again in its simplistic versions, brooks no rejection. ("The communists disdain to conceal their views and aims. They openly declare that their ends can be attained only by the forcible overthrow of all existing conditions." $)^{18}$

Once again we must distinguish between simplistic and sophisticated versions, for sophisticated Marxists are undoubtedly aware of the dangers of inadequate concern for individual autonomy or freedom, ${ }^{19.21}$ and Marx himself sees a community of autonomous people living together in peace, harmony, and true consciousness as the utopian "objective" of the inexorable march of history.

\section{Rawls's theory of justice}

A highly influential attempt to blend utilitarian theories and those theories of justice that respect autonomy-and indeed to incorporate the element of need of Marxist theories-is Professor John Rawls's theory of justice. ${ }^{223}$ As previously indicated, he argues that people coming together to work out a theory of justice for their society, and rendered impartial by the device of a "veil of ignorance" whereby they do not know what role they are to have in that society, would choose a system of justice whose first principle was that people should have the maximal liberty compatible with the same degree of liberty for everyone and whose second principle was that deliberate inequalities were unjust unless they worked to the advantage of the least well off.

\section{Reward for merit}

Finally, the claim that justice is essentially a matter of reward for individual merit-the view, for instance, of W D Ross ${ }^{24}$-remains plausible in at least some circumstances. For example, all competitions based on skill implicitly assume a principle of justice based on merit, including competitions to enter medical schools or obtain medical posts. Athletics competitions presuppose that "the best man (or woman) wins." The structure of wages in a capitalist society, whereby skilled work is rewarded more highly than unskilled work, again presupposes both that skills confer merit and that merit should be rewarded. On the other hand, can all distribution of benefits and burdens be fairly or justly determined on the basis of merit and demerit? In particular, there is no merit in being ill: should medical resources be allocated according to merit rather than illness?

So varied and so complex are theories of justice that more than with the other moral principles it would be hopeless even to suggest a generally acceptable substantive position. Instead it seems more useful to acknowledge that people's theories of justice are likely to continue to differ, I suspect largely on the basis of the relative weights they assign to the moral principles I have already outlined - that is, respect for autonomy, beneficence, and non-maleficence. I shall next look at allocation of scarce medical resources in the context of these various substantive theories of justice and in the light of Aristotle's formal principle of justice, which is implicitly accepted by them all.

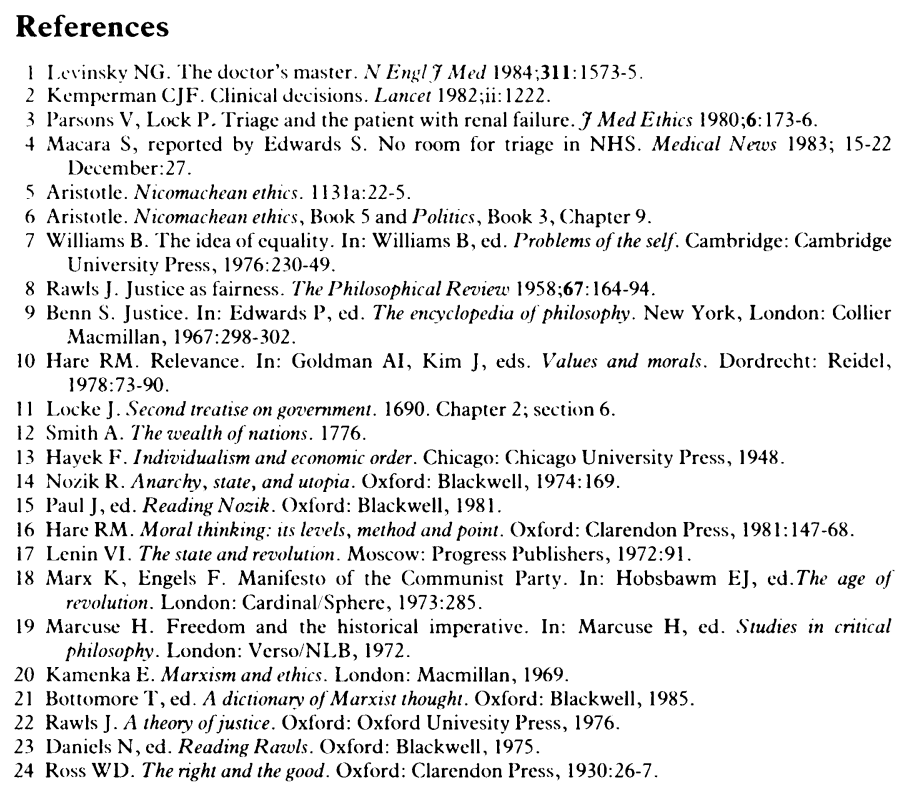

\section{Bibliography}

Beauchamp TL. Justice. In: Beauchamp TL, ed. Philosophical ethics: an introduction to moral philosophy. New York: McGraw-Hill, 1982:219-58.

President's Commission for the study of ethical problems in medicine. Securing access to health care. Washington: US Government Printing Office, 1983.

Campbell AV. Medicine, health and justice-the problem of priorities. Edinburgh: Churchill Livingstone, 1978.

\section{Correction}

Outbreak of poliomyelitis in Finland

In the fourth paragraph of the CDSC Report "Outbreak of poliomyelitis in Finland" 6 July, p 41) line 7 (p 42) should have read "regular Salk type trivalent poliovirus vaccine for all children under the age of 18 years." The total number of cases was larger than six. The full details of the outbreak will be published by the Finnish investigators later. We apologise for this error. 